\title{
Secretary Generals on recent ESHG presidents (2003-2015)
}

\author{
Helena Kääriäinen ${ }^{\star, 1}$ and Gunnar Houge ${ }^{2}$ \\ European Journal of Human Genetics (2017) 25, S20-S22; doi:10.1038/ejhg.2017.145
}

\begin{abstract}
Helena Kääriäinen (FI) and Gunnar Houge (NO). As secretary generals of ESHG during 2003-2015 we have had the privilege of working together with several very devoted presidents, many of whom have had great ideas about developing our society. In this short report we want to mention some aspects of their work or personalities. As you can see, the presidents represent the whole of Europe from Eastern/Central Europe to the UK and from Mediterranean to the Nordic countries. The gender ratio seems to be a bit old fashioned (4 females and 8 males). The reason to nominate candidates for presidency has usually been their activity in the society with also consideration given to having a diversity of regions and professional interests.
\end{abstract}

\author{
Helena: \\ 2003-2004 Veronica Van Heyningen \\ 2004-2005 Leena Peltonen \\ 2005-2006 Andres Metspalu \\ 2006-2007 John Burn \\ 2007-2008 Pier-Franco Pignatti \\ 2008-2009 Jean-Jaques Cassiman \\ 2009-2010 Dian Donnai
}

\section{Gunnar: \\ 2010-2011 Milan Macek Jr \\ 2011-2012 Jörg Schmidtke \\ 2012-2013 Stanislas Lyonnet \\ 2013-2014 Han Brunner \\ 2014-2015 Helena Kääriäinen}

Before she became secretary general, Helena worked together with previous secretary general Peter Farndon for a couple of years. Gunnar had the same period of overlap before he took over the task from Helena. In the following, we will briefly describe these excellent presidents and what they in particular have achieved for ESHG. Veronica Van Heyningen was, from a secretary general's point of view, an ideal president. She replied immediately to every question and really took the responsibility from the shoulders of a novice secretary general. One of her special interests was to establish the role of ESHG in the scientific community, including the Initiative for Science in Europe (ISE).

Leena Peltonen was a most inspiring person. She managed to encourage the Board to discuss much more actively than usually. Her strong connections with ASHG helped to bring these societies closer to each other. As a true scientist, she continued promoting the collaboration with the scientific community in Europe.

Andres Metspalu put his energy into education. He strongly promoted the idea that, in addition to ESHG Conferences, workshops and courses dedicated to one topic should also be organised. This has now become a tradition and several ESHG courses as well as ESHG supported regional courses have been organised. Andres also instigated the Educational Award in addition to the ESHG Award.

John Burn saw clearly that the society could not expand without professional help. He started negotiations with the Vienna Medical Academy which led to the satisfactory current situation, with Jerome del Picchia from VMA now part time executive officer of ESHG. This changed the workload of secretary general from slavery to a nice collaboration with a real professional. Another innovation of John Burn was the idea of joint membership of ESHG and a national society.

Pier Franco Pignatti's goal was to involve national human genetic societies more closely with ESHG. He organised the first meeting of NHGSs during an ESHG conference and this has become a lasting tradition ever since. These meetings have two aims: to enable ESHG to inform NHGSs about its plans, and to give NHGSs a forum to promote their ideas to ESHG and each other.

Jean-Jacques Cassiman's main goal in European genetics has been improving the quality of genetic services within EU and beyond. He involved ESHG in this work by starting a new committee, the Quality committee, the future role of which is still evolving.

Dian Donnai proved to be a real leader and organiser which led to regular Executive meetings with practical task-oriented minutes. She changed the subcommittees for different European specialties to ad hoc committees in order speed up lengthy processes. Towards the end of her presidency she raised the question on how to best involve the Board in the matters of ESHG; the results of this approach will be seen in the coming years.

Milan Macek was a very active president. Under his presidency, acceptance of medical/clinical genetics got through the EU 
bureaucracy, much to do with Milan's long-term commitment to achieve this. He was also active on other EU policy matters, especially those concerning the EU Professional Qualifications Directive. The latter may be instrumental in getting cross-border recognition of other genetic professionals (like CLGs and counsellors) without needing a consensus among all EU countries.

Jörg Schmidtke is the founding father of the European Board of Medical Genetics (EBMG). He also made an agreement the with European Society of Cardiology to collaborate on joint sessions at our respective annual meetings. This initiative has been followed through.

Stanislas Lyonnet wanted to reach out to Middle East and North African geneticists/scientists, that is, to provide reduced fee membership and participation at our meetings, and to promote ESHGsponsored educational efforts towards these countries.

Han Brunner was even more active as vice president than president. He was engaged in internal organisational matters, for example, to limit committee memberships to three year terms (to promote renewal and exchange), and to have our major focus on matters of real importance. Education was probably on top of his list of priorities, and his current chairing of the Educational Committee is a natural follow-up to this engagement.
The story of our time as secretary generals would not be complete without mentioning Andrew Read who has been treasurer of ESHG all the time. Keeping the figures in order is one of the key tasks of Executive Board and we have had the pleasure of relying on his expertise and wise counsel. However, in addition to calculating our euros, he has in his scientific and broadminded way contributed to all the development of ESHG.

Finally, the last author views Helena Kääriainen as the wise mother of ESHG of the early 21st century. He thinks her presidency was a natural follow-up to her dedication and long-term work to make ESHG into what it is today. Helena was and is, involved in almost everything, always with an ability to see matters from many angles. She now serves ESHG as president of the International Federation of Human Genetic Societies (IFHGS).

Helena Kääriäinen $^{1}$ and Gunnar Houge ${ }^{2}$

${ }^{1}$ National Institute for Health and Welfare, Mannerheimintie 166, 00300 Helsinki, Finland.

Tel: +35840 8309889;

E-mail: helena.kaariainen@thl.fi

${ }^{2}$ Universtiy of Bergen, Department of Clinical Science, Postboks 7804, 5020 Bergen, Norway.

Tel: +4755975444. 


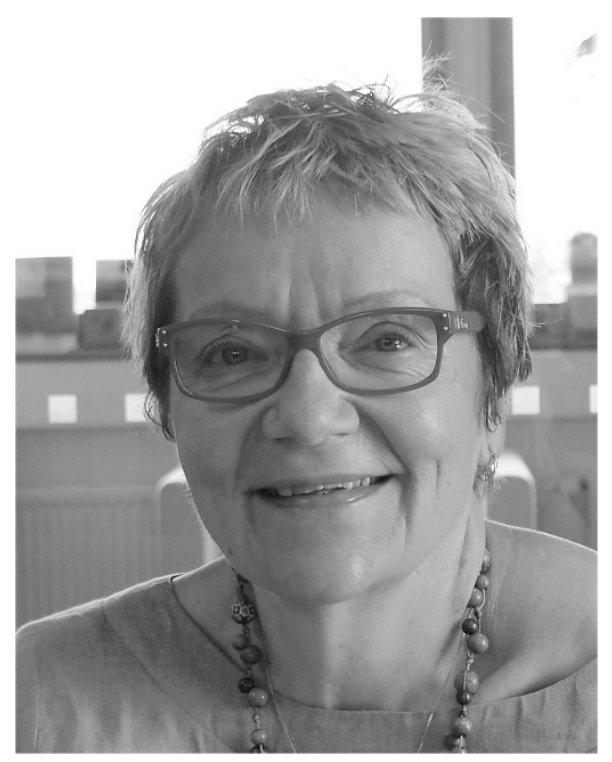

Helena Kääriäinen, $\mathrm{MD}, \mathrm{PhD}$, is a Research Professor at National Institute for Health and Welfare (THL), Finland. In THL her main task is related to planning of the implementation of genomic data from THL Biobank for the benefit of donors. She is a specialist in medical genetics and her research interests are rare diseases, genetic testing and counselling. In the European Society of Human Genetics (ESHG) she has been member of Public and Professional Policy Committee (PPPC) for several years since 2001 and later she was Secretary General of the Society. She acted as the President of ESHG 2014-15 and, at present, she is the President of International Federation of Human Genetics Societies.

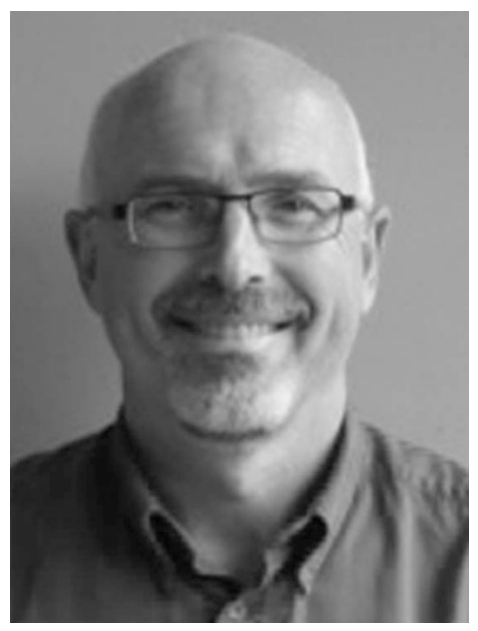

A biopic of Gunnar Houge appears earlier in this issue. 